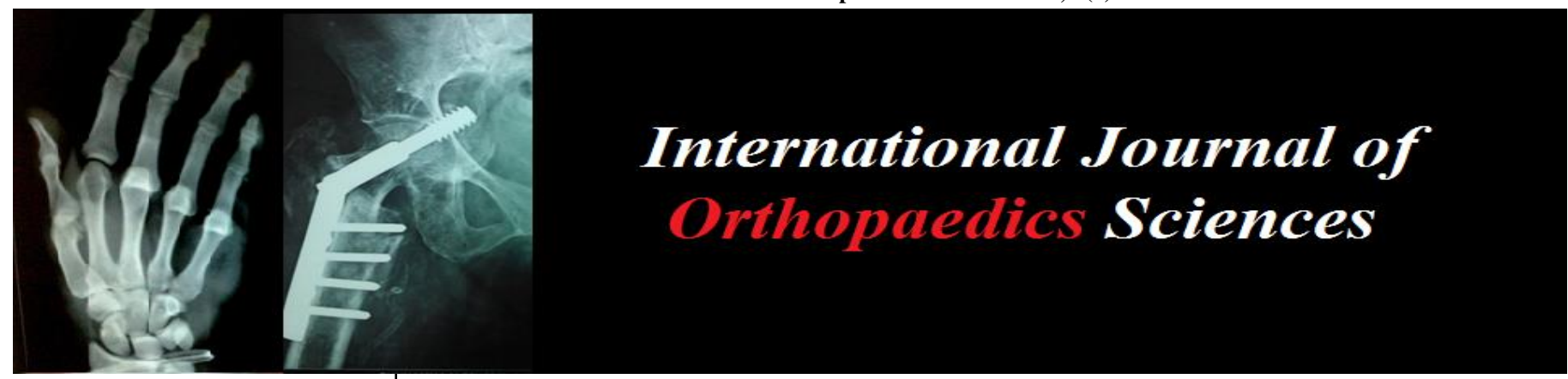

E-ISSN: 2395-1958

P-ISSN: 2706-6630

IJOS 2021; 7(3): 329-333

(C) 2021 IJOS

www.orthopaper.com

Received: 22-05-2021

Accepted: 24-06-2021

Dr. Ram Bhupal Varma R Assistant Professor, Department of Orthopaedics, Konaseema Institute of Medical Science, Amalapuram, Andhra Pradesh, India

Dr. Gurram Venkata Siva Naga Raja

Assistant Professor, Department of Orthopaedics, Konaseema Institute of Medical Science, Amalapuram, Andhra Pradesh, India
Corresponding Author: Dr. Gurram Venkata Siva Naga Raja

Assistant Professor, Department of Orthopaedics, Konaseema Institute of Medical Science, Amalapuram, Andhra Pradesh, India

\section{Evaluation of open reduction and internal fixation in closed fracture of talus: Seven -year observational study}

\section{Dr. Ram Bhupal Varma R and Dr. Gurram Venkata Siva Naga Raja}

DOI: https://doi.org/10.22271/ortho.2021.v7.i3e.2768

\section{Abstract}

Background: But because of the unique anatomical shapes and the vascular anatomy of the talus bone fracture of it is most challenging injury to manages. Despite the development in the field of diagnostics and improvement is surgical procedure, the complication is still frequent. As there is variability in the outcome of management of talus present study has been done to evaluate the outcome of open reduction and internal fixation in closed fracture of talus in our clinical scenario.

Method: Patients with fracture of talus admitted in the department of orthopaedics and trauma are enrolled for this study based on inclusion and inclusion criteria. Patient were evaluated both radiologically in anteroposterior, lateral, and mortise radiographs at two weeks, six weeks, twelve weeks, and six months postoperatively and clinically as well. All patients were followed upto two year and clinical evaluation done by AOFAS is a clinician-reporting tool.

Result: Among patients with type 2 fracture of neck of talus one has developed post-operative wound infection, one has developed post traumatic arthritis and two developed avascular necrosis. Among patients with type 3 fracture of neck of talus, two have developed post traumatic arthritis and two developed avascular necrosis. Among patients with type 4 fracture of neck of talus one has developed post-operative wound infection, and two developed avascular necrosis.

Discussion and Conclusion: From present study we can conclude that fracture of talus is uncommon with male predominance. Fracture of neck of talus is more common than body. Anteromedial and anterolateral approach was commonly used in surgical treatment. Avascular necrosis was common in type 4 fracture of neck of talus and post traumatic arthritis was found in type 3 fracture. As per ankle hindfoot scale clinical outcome fair and good outcome was equally found and $25 \%$ patient have poor outcome.

Keywords: fracture of talus, outcome, open reduction and internal fixation

\section{Introduction}

The talus is the link between the foot and leg through ankle joint. It is second largest tarsal bone which play important role in mobility of foot and ankle. Talus have no muscular attachment and most of the surface $(70 \%)$ is covered with articular cartilage. Fracture of talus is not common it is responsible for less than $1 \%(0.1 \%$ to $0.85 \%)$ of all fracture of human being and $3 \%$ to $6 \%$ of fracture of foot ${ }^{[1,2]}$. But because of the unique anatomical shapes and the vascular anatomy of the talus bone fracture of it is most challenging injury to manages. Blood supply to talus is rather tenuous because of lack of muscle attachment, so displaced fracture of neck where blood supply to talus body is interrupted can result in avascular necrosis and non-union ${ }^{[3]}$.

Despite the development in the field of diagnostics and improvement is surgical procedure, the complication is still frequent. Weight bearing per unit area of talus is very high and it has complex anatomical relation with other structure. So accurate reduction is essential to maintain articular surface integrity ${ }^{[4]}$.

Various literature review revealed that there is variability in the outcome of treatment of talus fracture. Biz, C., Golin, N., De Cicco, M. et al. has reported that the early complications included malunions $(21.4 \%)$ and wound problems $(25 \%)$; the late complications involved $\operatorname{AVN}(25 \%)$ and PTA $(78.6 \%)^{[5]}$. 
Halvorson JJ, Winter SB, Teasdall RD, Scott AT in his systematic review of literature has concluded that one third of these patients will develop AVN and two thirds will develop arthritis resulting in a $20 \%$ salvage procedure rate. Functionally, as defined by the classic Hawkins clinical criteria, almost one fourth of patients will end up with a poor outcome, with almost one half of patients having a fair or poor outcome ${ }^{[6]}$. Elgafy H, Ebraheim NA, Tile M, Stephen D, Kase $\mathrm{J}$ et al has reported that according to the Hawkins score, 35/80 feet achieved good/very good function versus 43 with the Mazur score. Radiographs showed ankle or subtalar arthrosis in two thirds of the patients. A normal range of motion was achieved in 18 ankle and 19 subtalar joints. The overall rate of talar necrosis was $9 / 80$ fractures ${ }^{[7]}$.

As there is variability in the outcome of management of talus present study has been done to evaluate the outcome of open reduction and internal fixation in closed fracture of talus in our clinical scenario.

\section{Material and Method}

This is a prospective observational study conducted in the department of orthopaedics Konaseema institute of medical science from February 2014 to March 2021.

Selection of patients: - Patients with fracture of talus admitted in the department of orthopaedics and trauma are enrolled for this study based on inclusion and inclusion criteria.

Inclusion criteria: -

Exclusion criteria

Age above 18 years

Both sexes pathological fracture open fracture

Closed Fracture of talus old neglected fractures

Fracture of body and neck of talus

Sample size: Based on exclusion and inclusion criteria 36 patients were enrolled during seven years of this study.

Ethics: Present study is approved by institutional ethics committee. A written informed consent was obtained from all patients before enrolling them for study.

Collection of data: All detail of the patient was recorded in predesigned Performa. After discharge from hospital patient was followed regularly both clinically and radiologically till full recovery.

\section{Method}

After admission in pre-operative planning, all basic investigation was done associated injuries were evaluated and treated. Initial radiological evaluation of the patient was done in anteroposterior (AP), mortise, and lateral views of the ankle and AP, oblique, and lateral views of the foot. For evaluation of fracture of talar neck which is oblique to the sagittal plane of the foot, a Canale radiographic view was taken. Fracture of talus was classified based on the involvement of the head, neck, or body. Fracture of body was further subdivided. Fracture of the neck of talus was classified based on method of Hawkins as modified by Canale ${ }^{[8]}$. After preoperative evaluation closed fracture patients were treated surgically. Surgical approach selected were anteromedial, anterolateral, combined anteromedial-anterolateral or posteromedial was based on type of fracture. After all preoperative preparation patients were shifted to operation theatre and positioned supine on operation table. A stable fixation was achieved through fixation as far as permissible based on fracture. In case of severe comminuted fracture of neck of talus with bone loss position crew was used. Selection of fixation devices were based on fracture pattern. Postoperative evaluation of fracture reduction was done radiographically. Patient were evaluated both radiologically in anteroposterior, lateral, and mortise radiographs at two weeks, six weeks, twelve weeks, and six months postoperatively and clinically as well. Mobilisation of foot started on first postoperative day without weight bearing, partial weight bearing was started from 6 weeks onward. All patients were followed upto two year and clinical evaluation done by AOFAS is a clinician-reporting tool ${ }^{[9]}$.

Statistical analysis: Data were recorded in excel sheet and statistical Analysis was done with software SPSS-14 version. Qualitative data were calculated as percentage and proportions. Quantitative data were expressed as mean \pm SD.

Result

During study period of seven years, we enrolled 32 patients as per selection criteria. During this period around 13500 orthopedic surgery was conducted in the department of orthopedics out of those 32 patients were operated for fracture of talus which is $.237 \%$ of total surgery,

Table 1: clinicodemographic profile of patients with fracture of talus

\begin{tabular}{|c|c|c|c|c|}
\hline \multicolumn{3}{|c|}{ Variable } & Number & Percentage \\
\hline \multirow{2}{*}{ Age $($ years $)($ mean $=36.54 \pm 14.21)$} & \multicolumn{2}{|l|}{ Less than 25} & 6 & 18.75 \\
\hline & \multicolumn{2}{|l|}{ More than 51} & 10 & 31.25 \\
\hline Sex & \multicolumn{2}{|l|}{ Female } & 10 & 31.25 \\
\hline Associated fracture & \multicolumn{2}{|l|}{ Malleolus fracture } & 4 & 12.5 \\
\hline Mechanism of fracture & \multicolumn{2}{|l|}{ Fall from height } & 12 & 37.5 \\
\hline \multirow{4}{*}{ Classification of fracture } & \multicolumn{2}{|l|}{ Body } & 10 & 31.25 \\
\hline & \multirow{3}{*}{ Neck (Hawkins as modified by Canale) } & Type 2 & 14 & 43.75 \\
\hline & & Type 3 & 8 & 25 \\
\hline & & Type 4 & 2 & 6.25 \\
\hline \multirow{4}{*}{ Approach to surgery } & \multicolumn{2}{|l|}{ anterolateral, } & 12 & 37.5 \\
\hline & \multicolumn{2}{|l|}{ anteromedial, } & 14 & 43.75 \\
\hline & \multicolumn{2}{|c|}{ combined anteromedial-anterolateral } & 5 & 15.625 \\
\hline & \multicolumn{2}{|l|}{ posteromedial } & 1 & 3.15 \\
\hline
\end{tabular}


As per table 1, mean age of patients with fracture of talus was $36.54 \pm 14.21$ years, number of patients below 25 years were $6(18.75 \%)$, number of patients between 26 to 50 years were $16(50 \%)$ and above 51 years were $10(31.25 \%)$. Fracture of talus was more common in male then female (2.2:1). Regarding other fracture associated with talus fracture, malleolus fracture was present in $4(12.50 \%)$ patients and calcaneus fracture was present in two $(6.25 \%)$ patients.

Road traffic accident was common mechanism present in $20(62.50 \%)$ patients and fall from height was mechanism of fracture in remaining patients. Regarding frequency of talus fracture as per classification of fracture, neck of fracture of talus is common then body of fractur (22vs 10$)(68.75 \%$ vs
$31.25 \%$ ). Regarding fracture of the neck of talus as per Hawkins as modified by Canale classification type 2 was present in 14(43.75\%) patients, type 3 was present in $8(25 \%)$ patients and type 3 was least common present in $2(6.25 \%)$ patients.

Most of the patients with fracture were reported for treatment within 5 days of injury. Only two patients $(6.25 \%)$ were reported for treatment after 10 days. Regarding approach to surgery, anteromedial approach was done in $14(43.75 \%)$ patients, anterolateral approach was done in 12(37.50\%) patients, combined anteromedial-anterolateral was used in $5(15.62 \%$ patients and posteromedial approach was used in $1(3.15 \%)$ patient.

Table 2: Outcome with respect to site of fracture

\begin{tabular}{|c|c|c|c|c|c|}
\hline \multicolumn{2}{|c|}{ Classification of fracture } & Infection & Non union & Post traumatic arthritis & Avascular necrosis \\
\hline \multicolumn{2}{|c|}{ Body } & 0 & 0 & 0 & 0 \\
\hline \multirow{3}{*}{ Neck (Hawkins as modified by Canale) } & Type 2 & 1 & 0 & 1 & 2 \\
\cline { 2 - 6 } & Type 3 & 0 & 0 & 2 & 2 \\
\cline { 2 - 6 } & Type 4 & 1 & 0 & 0 & 2 \\
\hline
\end{tabular}

Out of 10 patients with fracture of body of talus, there was no incidence of infection, nonunion, post traumatic arthritis and avascular necrosis in post-operative period. Among patients with type 2 fracture of neck of talus one has developed postoperative wound infection, one has developed post traumatic arthritis and two developed avascular necrosis. Among patients with type 3 fracture of neck of talus, two have developed post traumatic arthritis and two developed avascular necrosis. Among patients with type 4 fracture of neck of talus one has developed post-operative wound infection, and two developed avascular necrosis.
Table 3: Ankle hindfoot scale clinical outcome

\begin{tabular}{|c|c|}
\hline Variable & Number(percentage) \\
\hline Excellent & $4(12.5 \%)$ \\
\hline Good & $10(31.25 \%)$ \\
\hline Fair & $10(31.25 \%)$ \\
\hline Poor & $8(25 \%)$ \\
\hline
\end{tabular}

As per table 3 ankle hindfoot scale clinical outcome,4(12.5\%) patients have excellent outcome, $10(31.25 \%)$ patients have good outcome, $10(31.25 \%)$ patients have fair outcome and $8(25 \%)$ patients have poor outcome.
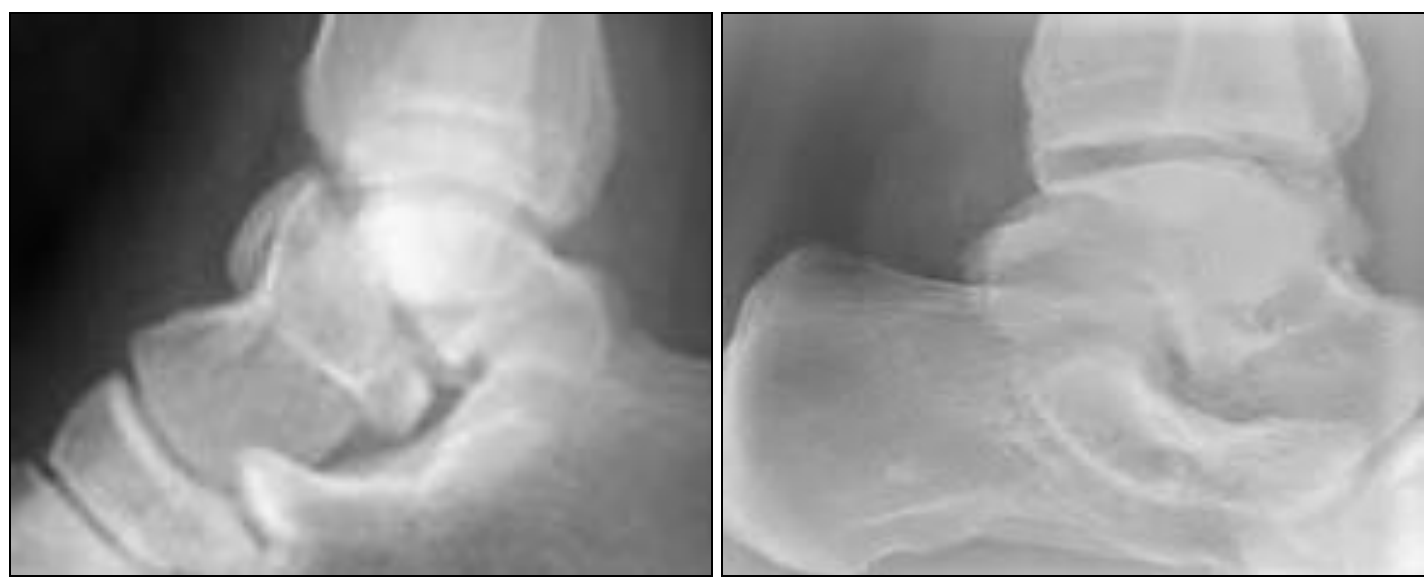

Fig 1: fracture talus body
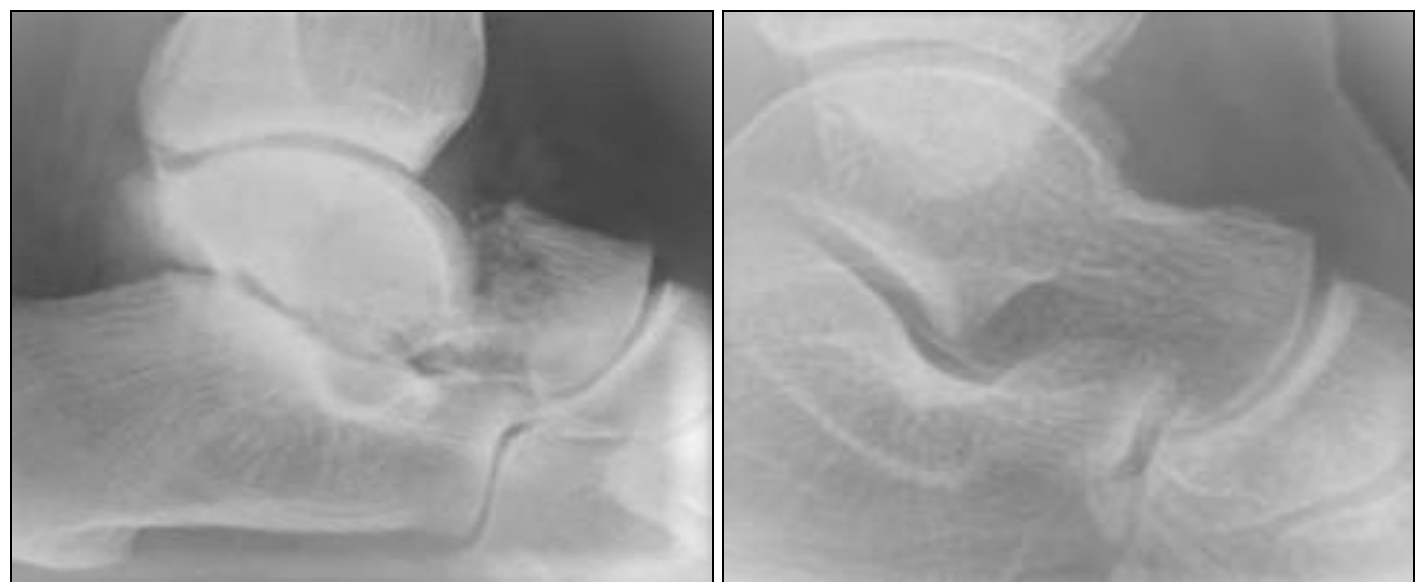

Fig 2: fracture talus neck 


\section{Discussion}

In present study 32 patients with fracture of talus were included for this study as per selection criteria. The incidence of fracture in this study was $.237 \%$. Fortin PT, Balazsy JE et $a l$ has reported that fracture of talus is uncommon and Talus fractures comprise approximately 0.1 to 0.85 percent of all fractures ${ }^{[1]}$ Mean age of patients with fracture of talus was $36.54 \pm 14.21$ years and maximum number of patients were between 26 to 50 years of age and there was male predominance. Sakaki MH, Saito GH, de Oliveira RG et al has reported that among the 23 patients evaluated, the ration of men to women was 4.8:1 (19 men and four women). Their mean age was 30.4 years, ranging from 18 to 49 years, this finding supports our study ${ }^{[10]}$. Regarding other fracture associated with talus fracture, malleolus fracture was present in $4(12.50 \%)$ patients and calcaneus fracture was present in two $(6.25 \%)$ patients. Road traffic accident was common mechanism present in $20(62.50 \%)$ patients, this finding is supported by the work of Russell TG, Byerly DW et al and Sundararajan SR, Badurudeen AA et al ${ }^{[11,12]}$.

Regarding frequency of talus fracture as per classification of fracture, neck of fracture of talus is common then body of fractur and as per Hawkins as modified by Canale classification type 2 fracture of neck is more common. This finding is supported by the work of Lindvall E, Haidukewych G, DiPasquale T, Herscovici D Jr, Sanders R ${ }^{[13]}$. But Dale JD, Ha AS, Chew FS et al has reported that the most common talar fracture location was the body $(61 \%)$. The most common body fractures were dome compression $(26 \%)$, lateral process (24\%), and posterior tubercle (21\%), this finding does not support our study ${ }^{[14]}$. Regarding approach to surgery, anteromedial approach was done in 14(43.75\%) patients followed by anterolateral approach which was done in $12(37.50 \%)$ patients, this finding is supported by the study of Whitaker C, Turvey B, Illical EM et al and Vallier HA, Nork SE, Benirschke SK, Sangeorzan BJ et al. ${ }^{[15,16]}$. Regarding Outcome with respect to site of fracture avascular necrosis was common in type 4 neck fracture and post traumatic arthritis was present in type 3 fracture. This finding corroborates with the finding of Biz, C., Golin, N., De Cicco, M. et al and Frawley PA, Hart JA, Young DA et al ${ }^{[5,17]}$. As per ankle hindfoot scale clinical outcome,4(12.5\%) patients have excellent outcome, $10(31.25 \%)$ patients have good outcome, $10(31.25 \%)$ patients have fair outcome and $8(25 \%)$ patients have poor outcome this finding is supported by work of Lindvall E, Haidukewych G, DiPasquale T, Herscovici D Jr, Sanders R. et al ,Vints W, Matricali G, Geusens E, Nijs S, Hoekstra $\mathrm{H}$ et al and Bardas CA, Benea HRC, Apostu D, Oltean-Dan D et al ${ }^{[13,18,19]}$.

\section{Conclusion}

From present study we can conclude that fracture of talus is uncommon with male predominance. Fracture of neck of talus is more common than body. Anteromedial and anterolateral approach was commonly used in surgical treatment. Avascular necrosis was common in type 4 fracture of neck of talus and post traumatic arthritis was found in type 3 fracture. As per ankle hindfoot scale clinical outcome fair and good outcome was equally found and $25 \%$ patient have poor outcome.

\section{Reference}

1. Fortin PT, Balazsy JE. Talus fractures: evaluation and treatment. J Am Acad Orthop Surg. 2001;9(2):114-27.

2. Vishay Mahadevan. pelvic girdle and lower limb, Gray's anatomical basis of clinical practice Churchill Livingstone Elsevier publication $41^{\text {th }}$ edition 2008;9(83):1436-37.

3. Halvorson JJ, Winter SB, Teasdall RD, Scott AT. Talar neck fractures: a systematic review of the literature. J Foot Ankle Surg 2013;52(1):56-61.

4. Mao $\mathrm{H}$, Wang $\mathrm{H}$, Zhao $\mathrm{J}$ et al. Initial assessment of treatment of talar posterior process fractures with open reduction and percutaneous fixation. Sci Rep 2020;10:20221 https://doi.org/10.1038/s41598-02077151-6

5. Biz C, Golin N, De Cicco $\mathrm{M}$ et al. Long-term radiographic and clinical-functional outcomes of isolated, displaced, closed talar neck and body fractures treated by ORIF: the timing of surgical management. BMC Musculoskelet Disord 2019;20:363 https://doi.org/10.1186/s12891-019-2738-2

6. Halvorson JJ, Winter SB, Teasdall RD, Scott AT. Talar neck fractures: a systematic review of the literature. J Foot Ankle Surg 2013;52(1):56-61.

7. Elgafy H, Ebraheim NA, Tile M, Stephen D, Kase J. Fractures of the talus: experience of two level 1 trauma centers. Foot Ankle Int. 2000;21(12):1023-9.

8. Canale ST, Kelly FB Jr. Fractures of the neck of the talus. Long-term evaluation of seventy-one cases. J Bone Joint Surg Am. 1978;60:143-56

9. Kitaoka HB, Alexander IJ, Adelaar RS, Nunley JA, Myerson MS, Sanders M. Clinical rating systems for the ankle-hindfoot, midfoot, hallux, and lesser toes. Foot Ankle Int 1994;15:349-53.

10. Sakaki MH, Saito GH, de Oliveira RG, Ortiz RT, Silva Jdos S, Fernandes TD et al. Epidemiological study on talus fractures. Rev Bras Ortop. 2014;49(4):334-9. doi: 10.1016/j.rboe.2013.07.002. PMID: 26229823; PMCID: PMC4511570.

11. Russell TG, Byerly DW. Talus Fracture. [Updated 2021 Jun 4]. In: StatPearls [Internet]. Treasure Island (FL): StatPearls Publishing 2021 Jan-. Available from: https://www.ncbi.nlm.nih.gov/books/NBK539687/

12. Sundararajan SR, Badurudeen AA, Ramakanth R, Rajasekaran S. Management of Talar Body Fractures. Indian J Orthop. 2018;52(3):258-268. doi: 10.4103/ortho.IJOrtho_563_17. PMID: 29887628; PMCID: PMC5961263.

13. Lindvall E, Haidukewych G, DiPasquale T, Herscovici D $\mathrm{Jr}$, Sanders R. Open reduction and stable fixation of isolated, displaced talar neck and body fractures. J Bone Joint Surg Am. 2004;86(10):2229-34. doi: 10.2106/00004623-200410000-00014. PMID: 15466732.

14. Dale JD, Ha AS, Chew FS. Update on talar fracture patterns: a large level I trauma center study. AJR Am J Roentgenol. 2013;201(5):1087-92. doi: 10.2214/AJR.12.9918. PMID: 24147480.

15. Whitaker C, Turvey B, Illical EM. Current Concepts in Talar Neck Fracture Management. Curr Rev Musculoskelet Med. 2018;11(3):456-474. doi: 10.1007/s12178-018-9509-9. PMID: 29974334; PMCID: PMC6105488.

16. Vallier HA, Nork SE, Benirschke SK, Sangeorzan BJ. Surgical treatment of talar body fractures. J Bone Joint Surg Am. 2004;86-A Suppl 1(Pt 2):180-92. doi: 10.2106/00004623-200409001-00008. PMID: 15466758.

17. Frawley PA, Hart JA, Young DA. Treatment outcome of major fractures of the talus. Foot Ankle Int 1995;16(6):339-45. doi: 10.1177/107110079501600605. 
PMID: 7550941

18. Vints W, Matricali G, Geusens E, Nijs S, Hoekstra H. Long-Term Outcome After Operative Management of Talus Fractures. Foot Ankle Int 2018;39(12):1432-1443. doi: 10.1177/1071100718790242. Epub 2018 Aug 22. PMID: 30132701.

19. Bardas CA, Benea HRC, Apostu D, Oltean-Dan D, Tomoaia G, Bauer T. Clinical outcomes after arthroscopically assisted talus fracture fixation. Int Orthop 2021;45(4):1025-1031. doi: 10.1007/s00264-02004859-5. Epub 2020 Oct 20. PMID: 33078205. 